\title{
Los consorcios en la Ley 2/2016, de 7 de abril, de Instituciones Locales de Euskadi tras la Ley 40/2015, de 1 de octubre, de Régimen Jurídico del Sector Público
}

Aizbea Atela Uriarte

DOI: https://doi.org/10.47623/ivap-rvap.110.2018.1.09

\begin{abstract}
Sumario: I. Introducción.-II. La evolución normativa del Consorcio: del consorcio local a los consorcios autonómicos y estatales y su regulación homogeneizada. 1. La primera etapa normativa del consorcio. 2. La segunda etapa de la evolución normativa del consorcio. 3. La tercera etapa normativa. - III. Los consorcios en la Ley 2/2016, de 7 de abril, de Instituciones Locales de Euskadi.1. El contexto normativo previo a la LILE. 2. Regulación de los consorcios en la LILE. 2.a). Tratamiento del consorcio en la Exposición de Motivos de la LILE. 2.b). La regulación del consorcio en el articulado de la LILE. -IV. Conclusiones.-V. Bibliografía.
\end{abstract}

\section{Introducción}

El 14 de abril de 2016 se publicó en el BOPV la Ley 2/2016, de 7 de abril, de Instituciones Locales de Euskadi(1) (LILE, en adelante), que entró en vigor al día siguiente a su publicación. Esta ley, de transcendencia incuestionable para el sistema de gobierno local en Euskadi, es importante, primero, porque es la primera ley autonómica de régimen local de la CAPV $y$, segundo, porque configura un sistema de gobierno local con clara visión institucional y con vocación de constituir una ley integral del régimen local vasco, regulando en un mismo texto normativo competencias y financiación incondicionada, algo que es ajeno a la praxis normativa sobre régimen local en España.

La sustantividad de esta materia en una ley en Euskadi ha supuesto simultáneamente, debido a la complejidad de su entramado institucio-

(1) BOPV, núm. 70, de 14 de abril de 2016, corrección de errores en $B O P V$, núm. 123, de 29 de junio de 2016. 
nal, tanto remover como aparcar tímidamente cuestiones institucionales tradicionalmente espinosas y controvertidas, para abordar la centralidad del municipio en el sistema de gobiernos locales, partiendo del previo reconocimiento por la doctrina de la autonomía política de los municipios y de las reivindicaciones en ese mismo sentido del municipalismo vasco (2).

En este contexto, la regulación del consorcio local en esta ley no es una cuestión de lo más importante para el legislador vasco, pero lo cierto es que tampoco estamos ante un asunto exento de interés, porque de la literalidad de la LILE puede inferirse su naturaleza de ente local, mientras que la reciente legislación básica estatal se orienta a configurarla como ente instrumental dentro de sector público institucional.

$Y$ es que, como recientemente ha puesto de manifiesto el profesor CASTILLO BLANCO, ésta no es una cuestión menor, pues de la correcta determinación de su naturaleza jurídica va a depender el régimen jurídico de sus actos, esto es: el control financiero y presupuestario, el régimen de personal, la contratación, etc., pero además y por extensión va a ser relevante respecto de los entes instrumentales y sociedades dependientes del mismo, que se verán o no sujetas a la legislación local para su constitución, funcionamiento y limitaciones, dependiendo de su naturaleza estatal, autonómica o local (3).

Por otra parte, la figura del consorcio, tal y como señala FERREIRA FERNÁNDEZ, cobra verdadera relevancia constitucional en tanto instrumento apto para la implementación de un marco estable de cooperación y colaboración entre las diferentes administraciones en la realización de aquellas actividades o servicios que revistan un interés común a todas ellas, garantizando con ello una mayor eficacia y eficiencia en la gestión de los asuntos públicos (4).

Analizaremos en este trabajo los impactos de la Ley 40/2015, de 1 de octubre, de Régimen Jurídico del Sector Público (LRJSP, en adelante) sobre la LILE, en materia de regulación del consorcio y su posible interpretación integradora.

(2) EUDEL «Bases para una ley Municipal de Euskadi», en sus apartado II, VII y X.

(3) CASTILLO BLANCO, F. A. «La incidencia de la nueva Ley de Régimen Jurídico del Sector Público en los instrumentos de cooperación del Estado Autonómico: especial referencia a los consorcios públicos". Web: http://laadministracionaldia.inap.es/noticia.asp?id=1507211 (última consulta 20/09/2017).

(4) FERREIRA FERNÁNDEZ, A. J., "Los consorcios del sector público autonómico. Un instrumento para la gestión conjunta de servicios públicos», en Dereito Monográfico: Estudios sobre la modernización administrativa, 2001, págs. 106 y 107-116. 


\section{La evolución normativa del Consorcio: del consorcio local a los consorcios autonómicos y estatales y a su regulación homogeneizada}

Siguiendo también en este punto a FERREIRA FERNÁNDEZ abordaremos la evolución normativa de la figura consorcial en tres etapas diferenciadas:

\section{La primera etapa normativa del consorcio}

Se caracteriza como ente local asociativo para la defensa de intereses locales.

Es pacífica en la doctrina atribuir a la legislación de régimen local el mérito de la regulación sistemática de la figura del consorcio.

Aunque es frecuente incurrir en el error de señalar que el primer texto legislativo de régimen local que regula esta figura es el Reglamento de Servicios de las Corporaciones Locales, aprobado por Decreto de 17 de junio de 1955 (RSCL, en adelante), lo cierto es que, como bien señala PARRA MUÑOZ, corresponde al Reglamento de Organización y Funcionamiento y Régimen Jurídico de las Corporaciones Locales de 1952, aprobado por Decreto de 17 de junio, el honor de ser el primer texto legislativo de régimen local que regula el consorcio (5). Posteriormente, tanto el Reglamento de Funcionarios de la Administración Local de 1952, aprobado por Decreto de 30 de mayo, aún vigente, en su art. 241, como el Reglamento de Bienes de las Corporaciones Locales de 1955, aprobado mediante Decreto de 27 de mayo, tienen previsiones relativas al consorcio.

No obstante, es cierto que no cabe duda de que le corresponde al RSCL el honor de haber sido el primer cuerpo normativo en regular, de forma general y sistemática, esta institución.

La ubicación de esta regulación del consorcio en el RSCL se contenía en los art. 37 a 40, en su Título III, que Ilevaba por rúbrica: «Servicios de las corporaciones locales".

Concretamente el art. 37 disponía:

"Las Corporaciones locales podrán constituir consorcios con Entidades Públicas de diferente orden con el fin de instalar o gestionar servicios de interés local».

(5) PARRA MUÑOZ, J. F., "A vueltas con la naturaleza jurídica del Consorcio», en Actualidad Administrativa, Sección Doctrina, Ed: La Ley, 2001, pág. 805. Efectivamente el Reglamento de Organización y Funcionamiento de las Entidades Locales de 1952 configura el Consorcio como un instrumento de cooperación de las Diputaciones Provinciales en la ejecución de obras y servicios de interés municipal, y concretamente su art. 172.20 disponía que le corresponde a la Diputación: "Constituir consorcios con Ayuntamientos de la provincia para la construcción de escuelas y viviendas de maestros, repoblaciones forestales, tendidos de redes de energía eléctrica, suministros de aguas y demás servicios u obras que afecten a varios Municipios". 
En la literalidad del precepto transcrito, hoy derogado expresamente por la LRJSP, no aparece el reconocimiento del consorcio como ente local, pero posteriormente la Ley 41/1975, de 19 de noviembre, de Bases del Estatuto de Régimen Local, reconocía ya al consorcio como ente local (6).

\section{La segunda etapa de la evolución normativa del consorcio}

Puede situarse entre los años 1985 y 2000, y se caracteriza por la superación de la calificación como ente local y por su consideración como ente asociativo para la gestión de intereses comunes, singularmente de los entes locales y de las Comunidades Autónomas.

La naturaleza jurídica del consorcio administrativo ha sido históricamente un tema polémico. La unanimidad doctrinal alcanzada en torno su naturaleza jurídica de ente local, tesis que defendió el profesor MARTíN MATEO en la década de los años setenta y principios de los ochenta(7), se rompió a raíz de la aprobación de la Ley 7/85, de 2 de abril, Reguladora de las Bases de Régimen Local (LRBRL, en adelante) (8).

Como es sabido esta ley excluye el consorcio del listado de entidades que gozan de la condición de locales en su art. 3 y ubica su regulación en el, actualmente derogado, art. 87, sito en el Capítulo II del Título VI de la LRBRL, dedicado a "actividades y servicios", lo cual hizo presagiar que para el legislador el consorcio es una simple modalidad para gestionar servicios públicos de forma asociada.

Asimismo el hecho de que el art. 87 de la LRBRL posibilitara la participación de entidades privadas sin ánimo de lucro en el consorcio, unido a que el art. 57 de la LRBRL mencionara al consorcio junto al convenio como fórmula de cooperación interadministrativa, parecía evidenciar una diversa consideración del consorcio administrativo respecto de la legislación de régimen local precedente. Además, esta interpretación quedaba reforzada por la falta de previsión de inscripción de esta entidad en el Registro de Entidades Locales creado por RD 382/1986, de 10 de febrero.

(6) Ley 41/1975, de 19 de noviembre, de Bases del Estatuto de Régimen Local. BOE, núm. 280, de 21 de noviembre de 1975, págs. 24342-24360. Web: https://www.boe.es/buscar/doc.php?id=BOE-A-197523920 (Última consulta 04/10/2017). Concretamente la base 39.4 disponía: «Los consorcios gozarán de personalidad jurídica propia y de la consideración de Entidades Locales».

(7) MARTÍN MATEO, R. «El consorcio como institución jurídica», en Revista de Administración Pública, núm. 61, 1970, págs. 9-42.

(8) CASTILLO BLANCO, F.A., es tajante al negar el carácter de ente local a los consorcios tras la entrada en vigor de la actual LRBRL y así lo argumenta desde sus primeros estudios. Póngase de ejemplo; "Los consorcios de entidades locales: análisis y valoración de la nueva legislación de régimen local», en Revista de Administración Pública, núm. 124, 1991, págs. 397-416. 
También el art. 110 del Texto refundido de las disposiciones vigentes en materia de Régimen Local, aprobado por Real Decreto Legislativo 781/1986, de 18 de abril, lo regulaba en similares términos a los de la LR$B R L$, exigiendo de novedoso que sus órganos de decisión se integrasen por representantes de todas las Entidades consorciadas en la proporción que se fijase en sus estatutos respectivos.

Posteriormente, la aprobación de la Ley 30/1992, de 26 de noviembre, de Régimen Jurídico y Procedimiento Administrativo Común (LRJPAC, en adelante), supuso la regulación general de esta figura fuera del ámbito local, ya que su art. 7 (luego el 6.5 con la modificación introducida por la Ley 4/1999, de 13 de enero) introdujo la posible creación de consorcios administrativos cuando la eficacia práctica de un convenio de colaboración entre la Administración del Estado y la Administración de las Comunidades Autónomas precisara contar con una organización ad hoc. Es lo que la doctrina denominó "deslocalización del consorcio", tal y como reconoceTOSCANO GIL(9).

La circunstancia de que el referido artículo de la LRJPAC únicamente recogiera dentro del ámbito subjetivo de los convenios de colaboración a la Administración General del Estado y a la Administración de las Comunidades Autónomas, unido a la remisión a la normativa local en todo lo relacionado a las relaciones interadministrativas con las entidades locales, llevó a algunos autores a concluir que en estos casos no sería posible la participación de una entidad local en los consorcios creados a su amparo, y de ahí entender que existen dos regímenes jurídicos diferenciados: el de los consorcios con participación de entes locales (entidades locales) y el de aquellos en que no haya tal participación (10).

La controversia viva se daba entre quienes mantenían que los consorcios regulados en la LRBRL seguían siendo entes locales y los que negaban tal calificación desde la entrada en vigor de la propia LRBRL.

Esta polémica sobre la naturaleza jurídica del consorcio pareció ser resuelta por la STS, de 30 de abril de 1999, Sala de lo Contencioso-Administrativo, Sección 7. ${ }^{\text {a }}$ (Ponente Exmo. Sr. D. Manuel Goded Miranda)(11). Esta sentencia vino a decir que si el legislador no había establecido expresamente que el consorcio no era una entidad local, ello era porque la

(9) TOSCANO GIL, F., «El consorcio administrativo en la encrucijada». REALA, Revista de Estudios de la Administración local y Autonómica, núm. 3, 2015. Web: https://revistasonline.inap.es/index.php?journal $=$ REALA\&page=article\&op=view\&path\%5B\%5D=10239\&path\%5B\%5D=10728 (Última visita 07/10/2017).

(10) Por todos, podemos reseñar a CASTILLO BLANCO, F. A., "Los consorcios administrativos: especial referencia a los consorcios de entidades locales en la legislación andaluza", en Revista Andaluza de Administración Pública, núm. 42, 2001, págs. 95-144 y PÉREZTORRENTE, J. A., "Los Consorcios», en Revista catalana de dret Públic, núm. 96, diciembre 1996, págs. 51-66.

(11) STS 2955/1999, de 30 de abril de 1999. Web: http://www.poderjudicial.es/search/contenidos.acti on?action=contentpdf\&databasematch=TS\&reference=3167380\&links=\%22MANUEL\%20GODED\%20 MIRANDA\%22\&optimize=20030906\&publicinterface=true (Última consulta 23/10/2017). 
diversidad de entes que lo podían integrar conduciría a que la naturaleza jurídica del consorcio administrativo dependiera del caso.

Por lo tanto, según esta sentencia, había que estar al análisis de los estatutos de cada consorcio para determinar si estábamos o no ante una entidad local, o bien ante una entidad de otro tipo, bien estatal o autonómica.

Para ello llamaba a estudiar criterios tales como el control efectivo de sus órganos de gobierno o la participación mayoritaria en el mismo, de tal manera que sería este control del consorcio por las entidades de un determinado ámbito territorial lo que determinaría su naturaleza jurídica: estatal, autonómica o local, en función de quién lo controlara (12).

De la Sentencia de referencia se extraen dos conclusiones:

I. La primera es que el hecho de que los consorcios no vengan incluidos como entidades locales en la enumeración del art. 3 no impide su clasificación como ente local, ya que el apartado segundo del art. 3 de la LRBRL no tiene carácter de cerrado y puede ser ampliado por las Comunidades Autónomas(13), y por lo tanto, la legislación autonómica puede configurar al "consorcio local» como ente local.

Sabemos, en este sentido, que el art. 3 de la LRBRL enumera los entes que forman parte de la llamada planta local, reconociendo la existencia de diversos tipos de entidades locales y diferenciando entre dos grandes categorías: los entes locales necesarios y los entes locales no necesarios o potestativos (14).

Siguiendo en este punto a TOSCANO GIL entendemos que la creación de entidades locales de cualquier tipo encuentra su fundamento en la potestad de autoorganización estatal, autonómica o local, reconocida por la Constitución Española, en cuanto forma parte del núcleo duro de la autonomía local de estas entidades(15).

(12) Esta STS, de 30 de diciembre de 1999, declara la nulidad de los estatutos del consorcio para el servicio de extinción de incendios, salvamentos y protección civil del Principado de Asturias por no atribuir la Secretaría a un Funcionario de Administración Local con Habilitación de carácter nacional, conforme a la reserva del puesto de secretario contenida en el art. 92.2 de la LRBRL. El argumento de la Sentencia es mantener que el consorcio es una entidad local y, como tal, su secretaría debe estar ocupada por un funcionario habilitado nacional.

(13) Esta interpretación tampoco era pacífica. En contra se encuentran argumentos en numerosos trabajos de CASTILLO BLANCO, que sostiene que su exclusión de la enumeración de entidades locales es determinante, debiendo considerarse una entidad pública de carácter o naturaleza singular pero ha de negarse en todo caso su naturaleza de ente local, en CASTILLO BLANCO, F. A. "Los consorcios de entidades......", op. cit.,, pág. 416.

(14) SANTAMARÍA PASTOR, J. A. Principios del Derecho Administrativo General. Tomo I, 2. ${ }^{a}$ Ed., lustel, Madrid 2009, págs. 527-528.

(15) TOSCANO GIL, F., "La definición del consorcio local como entidad local en la legislación autonómica», en Cuadernos de Derecho Local ( $O D L)$, núm. 27, Fundación Democracia y Gobierno Local, octubre de 2011, pág. 41 a pie de página. 
En la primera categoría, la de los entes locales necesarios, se encuentran el municipio, la provincia y la isla. Estas tres entidades se califican de necesarias porque su existencia está garantizada constitucionalmente en virtud de su reconocimiento expreso en el texto constitucional, y se consideran territoriales porque así se deriva de su regulación en el Título VIII de la Constitución, que se titula: «De la organización territorial del Estado", de la cual forman parte, así como del propio art. 3.1 de la LRBRL.

En la segunda categoría, recogida en el art. 3.2 de la LRBRL, están los Ilamados entes locales no necesarios: las entidades locales de ámbito territorial inferior al municipio, las comarcas $u$ otras entidades que agrupen varios municipios, las áreas metropolitanas y las mancomunidades de municipios.

Es en esta segunda categoría de entes locales donde pudieran tener razón de ser los consorcios, cuya existencia no está cubierta por la Constitución y no gozan de la cobertura de la garantía constitucional de su autonomía local; su creación se encuentra por lo tanto a disposición de la legislación autonómica.

II. La segunda conclusión que se deriva de la STS, de 30 de abril, de 1999, es que serán las "circunstancias concurrentes" en el consorcio las que deberán determinar si el consorcio constituido es o no local.

En definitiva, la doctrina contribuyó a sintetizar que pueden considerarse determinantes a la hora de atribuir al consorcio la naturaleza de ente local, entre otros, los siguientes criterios(16):

- No cabe duda alguna cuando todos los miembros del consorcio sean entidades locales (17).

- También podemos considerar el carácter local del consorcio cuando el mismo se haya creado para prestar alguno de los servicios o competencias atribuidas a las entidades locales en virtud de los arts. 25 y 26 de la LRBRL.

- Una postura ecléctica es la que adopta SOSA WAGNER, que distingue entre los consorcios constituidos por administraciones locales para la instalación o gestión de servicios de interés local, y los constituidos entre una o varias Administraciones Locales y las Administraciones del Estado y las Comunidades Autónomas que gestionen

(16) APARISI APARISI, M. C., "Los consorcios locales tras la LRSAL y la determinación de sus regímenes financiero y contable", en El derecho. Web: http:/www.elderecho.com/tribuna/administrativo/ Consorcios-locales-regulacion-regimenes-financiero-LRSAL_11_1026430001.html

(17) Debe aquí destacarse la heterogeneidad en la composición del consorcio como característica que la deferencia de las Mancomunidades. Así lo ha puesto de manifiesto tanto la doctrina. Por todos, MARTíNEZ FERNÁNDEZ, F., "Mancomunidades e Consorcios», en Revista Gallega de Administración Pública, núm. 34, enero-abril de 2005, págs. 205 y 206. Según él la naturaleza local del ente tampoco quebraría en aquellos consorcios creados con el único fin de gestionar servicios de competencia exclusiva local, por el hecho de integrase en el mismo una Administración de distinto nivel. 
intereses que no son estrictamente locales. Sólo serían locales los primeros, y en ellos la utilización del ordenamiento local es plena y no parece que pueda ofrecer duda: Administraciones Locales se asocian para fines de interés común y producen una persona jurídica, que al no poder ser una simple forma de gestión (porque puede utilizar las formas de gestión) tiene que tratarse justamente de un ente al que es de aplicación el ordenamiento local(18).

- Que sean los estatutos del consorcio los que expresamente atribuyan al consorcio el carácter de ente local.

- Parte de la doctrina considera que el consorcio puede considerarse local cuando se configura expresamente como tal por el legislador autonómico (19).

A esta STS, de 30 de abril de 1999, siguieron otras en el mismo sentido (20), y las leyes de algunas Comunidades Autónomas fueron positivando los criterios marcados en ella en sus respectivas leyes sobre régimen local, determinando cuándo un consorcio debía considerarse entidad local, pero también en las leyes de su Administración propia, a fin de fijar cuándo un consorcio era parte del sector público de una determinada Comunidad Autónoma (21).

Por lo tanto, en conclusión, podemos decir que sobre consorcios teníamos tres tipos de legislaciones:

La estatal contenida en el art. 6 de la LRJPAC, la autonómica derivada de su potestad de autoorganización, y finalmente la relativa a los consorcios locales, que se contenía en los art. 57 y 87 de la LRBRL, así como en alguna ley autonómica sobre régimen local, como en el caso de la ley andaluza de Autonomía Local.

En cualquier caso, la ubicación del consorcio en el sector público local tenía como consecuencia su sujeción a su ordenamiento jurídico a todos los efectos.

(18) SOSA WAGNER, F. "A vueltas con los consorcios», Web: http://www.administracionpublica. com/a-vueltas-con-los-consorcios/ (última consulta 07/10/2017).

(19) En este sentido el art. 149.2 de la ley 5/1997, de 22 de julio, de Administración Local de Galicia define al consorcio expresamente como entidad local y permite la creación de consorcios creados solamente por municipios.

(20) Podemos citar aquí, por ejemplo, la STSJ de Valencia, de 30 de junio de 2008, la STSJ de Castilla y León de 2002, así como la STS, de 28 de noviembre de 2007, que determina el carácter de entidad local del Consorcios deTransportes de Bizkaia.

(21) Sirva la mención de la Ley 5/97, de 22 de julio, de Administración Local de Galicia en sus art. 124 y ss. así como la Ley 20/2006, de 15 de diciembre, municipal y de Régimen Local de las Islas Baleares en su art. 2 así como la Ley 13/1989, de 14 de diciembre, de organización, procedimiento y régimen jurídico de la Administración de la Generalitat de Cataluña que, por primera vez, reconoce la posibilidad de constituir consorcios, en el ámbito autonómico, adelantándose incluso al legislador básico estatal. 


\section{La tercera etapa normativa}

Puede identificarse con el inicio del siglo XXI hasta la actualidad.

La indefinición de los criterios a tener en cuenta para ubicar a un determinado consorcio en la esfera del ordenamiento jurídico local, autonómico, o estatal, provocaba gran inseguridad jurídica. Esto llevó a la doctrina a reivindicar la determinación de un régimen jurídico básico aplicable a todos los consorcios, máxime cuando se encontró con la necesidad, cada vez más urgente, de abordar el control económico presupuestario de estas entidades que habían proliferado sobre todo en el ámbito local pero también en el autonómico.

En este sentido, en un primer momento, el art. 2.1.h) y la disposición adicional decimotercera de la Ley 47/2003, de 26 de noviembre, General Presupuestaria, establecieron el régimen presupuestario, económicofinanciero de contabilidad y control de los consorcios aplicable a los consorcios estatales.

Pero la gran convulsión normativa en relación al régimen jurídico del consorcio es provocada en los años 2013, 2014 y 2015: Primero, por la entrada en vigor de la Ley 27/2013, de 27 de diciembre, de racionalización y sostenibilidad de la Administración Local (LRSAL, en adelante), posteriormente por la Ley 15/2014, de 16 de septiembre, de racionalización del Sector Público y otras medidas de reforma administrativa (LRSP, en adelante), y por último por la actual LRJSP.

La entrada en vigor de la LRSAL el 31 de diciembre de 2013, introduce modificaciones importantes en relación a los consorcios en una doble dirección: general y local. Por una parte, añade una nueva disposición adicional a la LRJPAC aplicable a todos las consorcios administrativos, y por otra parte, modifica la LRBRL, concretamente sus art. 57 y 87, y por lo tanto, introduce modificaciones específicas aplicables únicamente a los consorcios locales.

La Disposición Final segunda de la $L R S A L$, que introdujo una nueva disposición adicional vigésima a la LRJPAC, regula con carácter general la creación y obligación de adscripción, así como el régimen presupuestario y de personal de los consorcios administrativos. En coherencia con la pretensión de racionalizar el sector público local, introducir medidas de reducción de la dimensión del sector público local y su obsesión por controlar su actividad y racionalizar su organización, tal y como se desprende de su Preámbulo, dispone una expresa y clara obligación de adscripción del consorcio siempre a una única Administración, aún en el caso de que también formaran parte del mismo entidades privadas sin ánimo de lucro. Para ello, introduce hasta un total de ocho criterios de prioridad diferentes para que, en base a alguno de ellos, sean los Estatutos los que determinen la adscripción del consorcio a una única Administración. 
Esta exhaustividad ha sido criticada por la doctrina porque conlleva una desagregación de criterios estrechamente relacionados entre sí, y que realmente, prescindiendo de la literalidad de la ley, se sintetizan en tres criterios de adscripción que son los siguientes: primero, el control mayoritario o efectivo de los órganos de gobierno del consorcio, segundo, la aportación económica mayoritaria al mismo y tercero, el mayor número de habitantes o extensión territorial (22). Parece por lo tanto que el debate sobre la naturaleza jurídica de ente local del consorcio se orilla y se centra en el alcance de la figura de la adscripción y sus consecuencias.

La adscripción a una u otra Administración Pública, más que por su calificación de ente local o no, es una cuestión de especial relevancia por cuanto la adscripción del consorcio al sector público de que se trate será determinante del régimen jurídico de aplicación a éste. Por tanto, su funcionamiento, el control económico financiero, las reglas que rijan su actividad, etc... van a venir determinadas por este aspecto esencial de su adscripción al «ente dominante».

Sin embargo, los problemas e incertidumbres siguen dándose, porque si bien del apartado 4 de la DA 20 de la LRJPAC se deduce en su literalidad que la adscripción supone la sujeción sólo al «régimen de presupuestación, contabilidad y control» de la Administración a la que se adscribe, la doctrina advierte dos tesis interpretativas, pues cabría interpretar una remisión en bloque a todo el régimen jurídico de la Administración de adscripción(23).

En lo que la doctrina más cualificada sí coincide, es en señalar que con la obligación de adscripción se acentúa la naturaleza de ente instrumental del consorcio en detrimento de su naturaleza de ente local, porque no de otra manera pueden entenderse las limitaciones en la creación de consorcios, así como la prohibición de tener personal propio sino solamente el reasignado y proveniente de las Administraciones que conforman el consorcio (24). El último pronunciamiento del TC, en relación al régimen jurídico de los consorcios y emitido con ocasión del enjuiciamiento de la LRSAL, avala también esta interpretación (25).

(22) CASTILLO BLANCO, F. A., "La nueva regulación de los consorcios públicos: interrogantes y respuestas sobre su régimen jurídico de su personal (1)", en Revista Vasca de Administración Pública, núm. especial 99-100, mayo- diciembre 2014, pág. 897.

(23) Así lo pone de manifiesto expresamente TOSCANO GIL, F., «El consorcio administrativo en la encrucijada", en REALA, Revista de Estudios de la Administración local y Autonómica, núm. 3, 2015. Web: https://revistasonline.inap.es/index.php?journal=REALA\&page=article\&op=view\&path\%5B\%5D =10239\&path\%5B\%5D=10728 (Última visita 07/10/2017).

(24) Por todos, JIMÉNEZ ASENSIO, Rafael, «¿Réquiem por los consorcios? Notas sobre el nuevo régimen jurídico de los consorcios tras la LRSAL, blog de 7 de junio de 2014, Web: www.estudiconsultoria.com (Última consulta 10/7/2014).

(25) FJ 7 de la STC 93/2017, de 6 de julio. Recurso de Inconstitucionalidad 2006-2014, interpuesto por el Consejo de Gobierno de la Generalitat de Cataluña. EI TC, con ocasión del enjuiciamiento de la LRSAL se ha pronunciado sobre la constitucionalidad de esta DA 20. ${ }^{a}$ de la LRJPAC, 
En una segunda dirección, recordemos que la LRSAL opera una modificación en la LRBRL, y en lo que nos ocupa ahora modifica su art. 57, configurando el consorcio local como instrumento de cooperación subsidiario, lo cual ha llevado a la persistencia crítica de una dualidad de regímenes jurídicos en relación al consorcio según sea éste local o no, porque además en este momento permanecía vigente el art. 87 de la LRBRL.

En este sentido se imponen limitaciones a la creación de nuevos consorcios además de otras limitaciones contenidas en las DDAA 9. ${ }^{a}, 13^{a} \mathrm{Y}$ $14 .^{\text {a }}$ de la LRSAL, como medidas de redimensionamiento dentro del sector público local. Se prohíbe a las entidades instrumentales del sector público local, como son los consorcios locales, integrarse en otras entidades, incluyendo asimismo la prohibición de participar en otros consorcios. Se imponen además, limitaciones al número máximo de miembros de los órganos de gobierno del consorcio y a la existencia y retribuciones del personal directivo, medidas que suponen, en todo caso limitación de la autonomía y discrecionalidad de las Administraciones Públicas para decidir, en el ejercicio de su potestad de autoorganización, la forma de cooperación, viéndose ahora obligadas a motivar si en lugar de elegir un convenio deciden constituir un consorcio, con todas las limitaciones que además exige la nueva legislación.

El art. 57, en su dimensión de instrumento de cooperación, impone restricciones de futuro para la constitución de nuevos consorcios, porque solamente podrán constituirse cuando la misma finalidad pretendida no pueda alcanzarse mediante un convenio y siempre que, en términos de eficacia económica, la utilización de consorcio permita una asignación más eficiente de los recursos económicos. Además se exige que deberán mejorar la eficiencia en la gestión pública, eliminar duplicidades adminis-

desestima el recurso de inconstitucionalidad interpuesto contra el mismo y señala que la finalidad uniformadora de la obligación de adscripción pretende dar cumplimiento a los principios de seguridad jurídica y responsabilidad de los poderes públicos, en conexión con los principios de legalidad y control del gasto público. Es decir, esta obligación genérica de adscripción trata de superar la dificultad de exigir responsabilidades públicas a las Administraciones que operan a través de instrumentos de Administración "mixta». Y en relación a la fijación de los criterios para determinar la Administración a la que deben adscribirse los consorcios puntualiza que no supone una invasión de las competencias de la CA (la Generalitat en este caso) en materia de autoorganización en virtud de que: "no establece por sí un concreto régimen sobre presupuestos, contabilidad, control y personal que pudiera llegar a invadir las competencias de las Comunidades Autónomas respecto de la organización de sus servicios. Se limita a indicar que a esas cuestiones resultará aplicable el régimen jurídico del nivel correspondiente a la Administración de adscripción. Consecuentemente, si la Administración de adscripción es autonómica, la legislación aplicable será la de la Comunidad Autónoma, sin perjuicio de que pueda serlo también la básica o general dictada por el Estado para el conjunto de las Administraciones públicas». $B O E_{\text {, }}$ núm. 191, de 11 de agosto, págs. 81225-81230. Web: https://www.boe.es/boe/dias/2017/08/11/ pdfs/BOE-A-2017-9652.pdf (Última consulta 02/03/2018). 
trativas y cumplir con la Ley de Estabilidad Presupuestaria y Sostenibilidad Financiera (26).

En términos contundentes CASTILLO BLANCO denuncia que esta previsión precisamente se inclina por configurar dos tipos de regímenes jurídicos para la institución consorcial: los participados por entes locales con clara desconfianza y los que no lo sean. Además, denuncia la mutación jurídica del consorcio en el ámbito local, pues ahora, junto a ser un instrumento de cooperación lo puede ser de coordinación, de acuerdo con lo dispuesto en el art. 26.2 de la LRBRL.

Lo cierto es que la jurisprudencia constitucional ha avalado esta previsión del art. 57 de la LRBRL desde la primera de las numerosas sentencias recaídas sobre la LRSAL, argumentando que el art. 149.1.18 puede dar cobertura a una legislación básica estatal que incida sobre los entes locales con autonomía constitucionalmente garantizada, que proyecte los principios de eficacia, eficiencia y estabilidad presupuestaria sobre el régimen local, o que articule una ordenación básica de las relaciones interadministrativas de cooperación, señalando expresamente que los consorcios no son ajenos a ninguno de estos aspectos, y que el carácter bifronte del régimen local permite al Estado regular fórmulas cooperativas, por cuanto que el nivel local forma parte de la organización territorial del Estado.

La jurisprudencia aludida señala además que la preferencia asignada a la fórmula convencional en detrimento de la consorcial puede discutirse políticamente, pero constituye una directriz directamente encaminada a desarrollar una política de contención de personificaciones públicas que se sitúa dentro de los amplios márgenes de configuración legislativa que abre la Constitución, y amparan los apartados 14 y $18 \mathrm{del}$ art. 149.1 CE (27).

En 2014, de forma provisoria, fue la LRSP la que introdujo modificaciones en el régimen jurídico de los consorcios en la línea iniciada por la LRSAL. Pretende establecer un régimen jurídico básico que discipline y facilite el derecho de separación de los miembros de consorcio, así como su disolución. Sin embargo, este cuerpo legal introduce también, como causa específica de separación para los consorcios locales, el ejercicio del derecho de separación de un municipio que deje de prestar un servicio que forme parte del objeto del consorcio, en clara alusión a las compe-

(26) Ley Orgánica 2/2012, de 27 de abril, de Estabilidad Presupuestaria y Sostenibilidad Financiera. $B O E$, de 30 de abril, de 2012. Web: https://www.boe.es/boe/dias/2012/04/30/pdfs/BOE-A-2012-5730. pdf (Última consulta 02/03/2018).

(27) Deben reseñarse los FFJJ 5 y 8 de la STC 41/2016, de 3 de marzo. BOE, núm. 85, de 8 de abril, págs. $25009-25010$ y 25020 . Web: https://www.boe.es/boe/dias/2016/04/08/pdfs/BOE-A-2016-3407.pdf (Última consulta 02/03/2018). 
tencias del art. 7.4 de la LRBRL o de aquellas que salen de la órbita municipal y pasan a la autonómica, según la dicción del art. 25.2 de la LRBRL.

En este aspecto, el debate sobre la naturaleza de ente local de los consorcios locales parece desvanecerse, sobre todo porque la regulación básica es uniformadora para todos los consorcios, pero no se entiende muy bien que la Ley 40/2015 no derogue expresamente la normativa introducida por la LRSAL, queriendo mantener la compleja dualidad de regímenes jurídicos.

Por último, a nivel estatal, en 2015, se aprueba la actual LRJSP, que, en sus art. 118 a 127, regula específicamente el régimen jurídico de los consorcios con carácter básico.

Siguiendo a TOSCANO GIL compartimos que esta ley encuentra su fundamento constitucional en el art. 149.1.18, bases del régimen jurídico de las Administraciones Públicas, si bien en conexión con el art. 135 de la Constitución, y esto a pesar de que el propósito expansivo del Estado recurre a los arts. 149.1.13 y 149.1.14 de la CE para otorgar título habilitante a esta regulación(28). En este sentido, el régimen jurídico de los consorcios contenido en esta ley tiene carácter básico, de acuerdo con lo dispuesto en el apartado 2 de su disposición final decimocuarta, salvo en lo relativo a la creación en los que participe la Administración General del Estado ex art. 123.2 y a sus propias excepciones nominativas.

Esta norma básica viene a realizar mayormente una tarea de recopilación y refundición de la regulación de estas entidades introduciendo pocas innovaciones, y da así satisfacción a las reivindicaciones de gran parte de la doctrina administrativista (29). Como novedad reseñable el art. 118.1 introduce la posibilidad de que puedan formar parte del consorcio entidades privadas sin ánimo de lucro que persigan fines de interés público, en cuyo caso el consorcio no tendrá ánimo de lucro y deberá adscribirse a la Administración Pública que resulte de acuerdo a los criterios legales establecidos.

Lo que aquí importa es el sorprendente orden de prelación de fuentes que recoge la literalidad del art. 119 , apartado 1 y 2 , estableciendo el ca-

(28) TOSCANO GIL, F., "Otra vez los consorcios administrativos: novedades introducidas por la Ley 40/2015 de régimen jurídico del sector público", en Revista Vasca de Administración Pública, núm. 105, Mayo-Agosto 2016, pág. 476.

(29) Así lo reivindica, por ejemplo CASTILLO BLANCO, F. A., en "La incidencia de la nueva Ley de Régimen Jurídico del Sector Público en los instrumentos de cooperación del Estado Autonómico: especial referencia a los consorcios públicos", cuando señala que los consorcios han debido de desarrollar sus funciones en medio de un notable vacío normativo que ha provocado que, tanto en su procedimiento de constitución, como en aspectos de la gestión ordinaria, particularmente en el ámbito del control presupuestario y de la gestión de personal, hayan surgido numerosos conflictos derivados de la indeterminación de su naturaleza jurídica y de la imprecisión de sus estatutos. Web: http://laadministracionaldia.inap.es/noticia.asp?id=1507211 (Última consulta 20/09/2017). 
rácter supletorio contenido en la legislación de régimen local y disponiendo que el régimen de fuentes será el siguiente: Lo dispuesto en la LRJSP, la normativa autonómica general y de régimen local, y, por último, lo dispuesto en sus Estatutos, ex art. 119. Lo más relevante es la declaración de supletoriedad de las normas previstas en la legislación local, según su art. 119.3. Más específicamente, las que se contienen en los art. 26, 57, DA 9. ${ }^{\circ}$ y $12 .^{a}$ de la LRBRL y en las DA $13 .^{a}$ y $14 .^{a}$ de la LRSAL.

Esta dicción ha removido cimientos jurídicos que parecían pacíficos en la doctrina académica, pues ocurre el caso insólito y novedoso en nuestro derecho, cual es el que se generan normas básicas de diferente prelación en rango legal, tal y como ávidamente ha puesto de relieve GARCÍA RUBIO (30).

Este esquema de integración normativa ha sido duramente criticado. Entre otros, el profesor JIMÉNEZ ASENSIO alude al incomprensible recurso a la supletoriedad, que es propia de la dialéctica integradora entre diferentes ordenamientos jurídicos, pero no aludible como método de relación e integración dentro de un mismo sistema jurídico, como lo es el estatal, en un supuesto en el que, en base al principio de temporalidad y/o especialidad la legislación ulterior no ha derogado expresamente preceptos, también básicos, de la materia "bases del régimen local» contenidas en la LRBRL y en la LRSAL (31).

La LRJSP sólo deroga expresamente el art. 87 de la LRBRL, no los demás preceptos, ni de la LRBRL ni de la LRSAL. Si entre la LRJSP, la LRBRL y la LRSAL no hay jerarquía y ostentan la misma posición ordinamental, no se entiende la solución aportada por el art. 119.3, máxime cuando, como señala VELASCO CABALLERO, es difícilmente asumible que siendo la LRJSP fruto de la misma iniciativa política que dio lugar a la compleja LRSAL pretenda su derogación (32).

Por otro lado, la novedosa posibilidad introducida por la ley, sin ningún tipo de criterio, de que participen entidades privadas con ánimo de lucro casa poco, según GARCíA RUBIO, con el mantenimiento de su naturaleza administrativa, porque el interés general del art. 103 de la Constitución es escasamente compatible con los legítimos intereses particulares

(30) GARCÍA RUBIO, F., "Los consorcios locales en el proyecto de ley de Régimen Jurídico del Sector Público. Reflexiones necesarias", en Documentación Administrativa. Nueva época, núm. 2, enero-diciembre, 2015. Web: https://dialnet.unirioja.es/servlet/autor?codigo=193103 (Última consulta 23/10/2017).

(31) JIMÉNEZ ASENSIO, R., «El sector Público Local tras la Ley 40/2015: retos inmediatos y cuestiones abiertas(1)", blog: LA MIRADA INSTITUCIONAL, de 22 de septiembre de 2016. Web: https://rafaeljimenezasensio.com/2016/09/ (Última consulta 28/12/2016).

(32) VELASCO CABALLERO, F., "Los convenios locales en la nueva ley 40/2015, de Régimen Jurídico del Sector Público". Instituto de derecho Local. UAM blog. 13 de noviembre de 2015. Web: http:// www.idluam.org/blog/?p=363 (Última visita 07/10/2017). 
de las empresas que pudieran formar parte del consorcio, y podría también generar colisiones con otras instituciones como las empresas mixtas y los patrocinios (33).

En conclusión, el alcance de las últimas reformas operadas por el legislador básico estatal tampoco es muy clarificador, sino más bien al contrario, hace pervivir la gravosa regulación del consorcio local, y plantea como problema jurídico la relación entre la legislación básica general y la legislación básica específica sobre el consorcio adscrito a una entidad local.

Además es pacífico que la reciente normativa estatal provoca un incremento de la regulación del régimen jurídico del consorcio que deja menos sitio a la autorregulación por las entidades consorciadas mediante sus estatutos, y en la medida en que esta regulación opera a través de normas básicas, no sólo se deja menos espacio a los estatutos de las entidades consorciadas sino también a la regulación por las Comunidades Autónomas con competencia en la materia.

Por otro lado, es evidente que en la regulación básica estatal ha pesado más la dimensión instrumental que la vertiente de técnica de cooperación interadministrativa del consorcio, y sin embargo, a pesar de todas las limitaciones y restricciones impuestas, parece que la potencialidad del consorcio adquiere más visibilidad en el mundo local a través del art. 26.2 de la LRBRL introducido por la LRSAL, porque prevé su utilización como fórmula de gestión compartida bajo la coordinación provincial en municipios de menos de 20.000 habitantes, provocando su perversa y paradójica mutación: de técnica de cooperación interadministrativa a técnica de coordinación para la gestión integrada de servicios municipales.

\section{Los consorcios en la Ley 2/2006, de 7 de abril, de Instituciones Locales de Euskadi}

\section{El contexto normativo previo a la LILE}

Debido al entramado interinstitucional de Euskadi, el sistema de fuentes del derecho adquiere complejidad respecto del de régimen común. Esto es, porque aparecen como actores normativos de especial cualificación las instituciones forales de los Territorios Históricos (Juntas Generales y Diputaciones Forales), que tienen competencia sobre régimen local conjuntamente con el Parlamento Vasco.

(33) GARCíA RUBIO, F., "Los consorcios locales en el proyecto...." op. cit., pág. 17. 
Tanto la Constitución como el Estatuto de Autonomía del País Vasco (34) (EAPV, en adelante), aprobado por Ley Orgánica 3/1979, de 18 de diciembre de 1979, confieren competencias al Estado ex art. 149.1.18 y a la Comunidad Autónoma del País Vasco ex art. 148,1.1. ${ }^{a}$ y 2. ${ }^{a}$ sobre régimen local. En lo que aquí interesa, confiere al Estado competencia sobre las bases del régimen jurídico de las administraciones públicas y la legislación básica sobre contratos y concesiones administrativas, mientras que dispone que las Comunidades Autónomas pueden asumir competencias sobre la organización de sus instituciones de autogobierno y sobre las funciones que correspondan a la Administración del Estado sobre las corporaciones locales, y cuya transferencia se permita por la legislación sobre régimen local.

Con carácter particular para Euskadi, la DA 1. ${ }^{a}$ de la Constitución establece que ésta ampara y respeta los derechos históricos de los territorios forales y que la actualización general del régimen foral se lleva a cabo, en su caso, en el marco de la Constitución.

Esta referencia, tal y como señala DEL GUAYO CASTIELLA, es imprescindible en materia de instituciones locales por cuanto la estructura del autogobierno vasco es tripartita: las instituciones comunes vascas, los territorios históricos y los municipios y demás entidades locales(35). Por su parte, el art. 10.4 del EAPV confiere competencia exclusiva a Euskadi sobre régimen local y su administración local, sin perjuicio de lo establecido en el art. 149.1.18 de la Constitución.

Además, su art. 3 dispone que cada uno de los Territorios Históricos (TTHH, en adelante) que integran el País Vasco puede, en el seno del mismo, conservar o en su caso restablecer y actualizar su organización e instituciones privativas de autogobierno. En igual sentido, el art. 39 de la LRBRL dispone que los TTHH conservan su régimen peculiar en el marco del EAPV, y su DA 2. ${ }^{\text {a }}$ dispone que los TTHH vascos organizan libremente sus propias instituciones, y amparan y garantizan las peculiaridades históricas de las entidades locales de sus territorios. De ahí la importancia de determinar la naturaleza jurídica de los consorcios como ente local, pues sobre su régimen jurídico tendrían competencia exclusiva los TTHH al amparo constitucional.

Los TTHH han dictado Normas Forales en desarrollo de la competencia exclusiva sobre demarcaciones municipales y supramunicipales que les otorga el art. 7.a) de la Ley 27/1983, de 25 de noviembre, que versa sobre

(34) BOE, núm. 306, de 22 de diciembre de 1979.

(35) DEL GUAYO CASTIELLA, I., "Formas de gestión de los servicios públicos locales en la Ley 2/2016, de Instituciones Locales de Euskadi», en Revista Vasca de Administración Pública, núm. 107II, enero-abril 2017, pág. 303. 
las relaciones entre las instituciones comunes de la Comunidad Autónoma y los órganos forales de sus Territorios Históricos (36).

Por otro lado, la LILE ha sido denominada por la doctrina más cualificada en la CAPV como ley que actualiza derechos históricos; concretamente actualiza el derecho histórico relativo al régimen jurídico del municipio foral(37). Debido a que el desarrollo del municipio en Euskadi ha estado intensamente ligada al de los TTHH se plantea en qué medida las diferencias recogidas en la LILE quedan amparadas por esos derechos históricos y avaladas por la DA1. ${ }^{\text {a }}$ de la Constitución, y también, por lo tanto, por la propia legislación básica estatal recogida en la LRBRL, la LRSAL y actualmente en la LRJSP.

Lo cierto es que a la luz de las últimas modificaciones legislativas de ámbito estatal, abordadas en el epígrafe anterior, la polémica sobre la naturaleza jurídica de los consorcios locales cede en términos generales, pero reaparece en la CAPV en el momento en que, apenas trascurridos escasos seis meses desde la entrada en vigor de la LILE, entra en vigor la mentada LRJSP, con una clara tendencia preventiva a la creación de los consorcios, como hemos expuesto, configurándolos claramente como entidad instrumental que forma parte del sector público institucional, e instrumento de cooperación subsidiario a otras formas de cooperación interadministrativa.

Ya hemos constatado que LRSAL y LRJSP son fruto de una misma iniciativa política y que sólo se deroga expresamente el art. 87 de la LRBRL.

Por otro lado, según VELASCO CABALLERO, cuando la LRJSP entra en conflicto con leyes locales autonómicas aprobadas para el desarroIlo de la LRSAL, si bien en un primer momento podría pensarse que la LRJSP desplaza o deroga desde su entrada en vigor a estas leyes autonómicas, esto llevaría a concluir que las leyes autonómicas de desarroIlo de la LRSAL habrán quedado derogadas a la entrada en vigor de la LRJSP. Sin embargo, hay que tener en cuenta que las leyes autonómi-

(36) En Bizkaia se aprobó, en este sentido, la Norma Foral 3/95, de 30 de marzo, reguladora de las entidades de ámbito supramunicipal de Bizkaia. $B O B$, núm. 73, de 18 de abril de 1995, que dispone la obligatoriedad de inscripción de los consorcios en el Registro de entidades locales del Territorio Histórico de Bizkaia. Por su parte, en Gipuzkoa se aprobó la Norma Foral 6/2007, de 10 de abril, reguladora de las entidades de ámbito supramunicipal del Territorio Histórico de Gipuzkoa. BOG, núm. 78, de 23 de abril de 2007; en su art. 18.4 considera a los consorcios locales que prestan servicios locales entes locales cuyo régimen jurídico se rige por la ley de régimen local. En Álava, no hay Norma Foral específica que regula la figura del consorcio pero son varias las normas que se refieren a ellos; Norma Foral 4/1989, de 19 de julio, de las Haciendas Locales, la Norma Foral 4/2015, de 11 de febrero, de singularidad foral en la aplicación de las medidas de racionalización y sostenibilidad de la Administración Local en el Territorio Histórico de Álava, así como el Decreto Foral 56/2015, de 3 de noviembre, que aprueba el marco regulatorio contable de sus entidades locales.

(37) LARRAZABAL BASÁÑEZ, S. «Zume hauekin...ekin lanari. Reflexiones sobre la génesis, naturaleza e inserción de la Ley de Instituciones Locales de Euskadi en el peculiar sistema de fuentes del derecho Vasco", en Revista Vasca de Administración Pública, núm. 107-II, enero-abril 2017, pág. 43. 
cas, en la medida que desarrollan normas básicas estatales (las de la LRSAL, por ejemplo), vinculan su eficacia a la propia existencia de las normas básicas de régimen local, entonces tampoco se pueden considerar derogadas las normas autonómicas de desarrollo de las leyes básicas estatales. Otra consideración llevaría al absurdo de considerar que la LRJSP deroga las normas secundarias sobre la materia (las autonómicas de desarrollo), pero no las normas en las que se apoyan las normas de desarrollo (las normas básicas estatales sobre régimen local) (38).

Realmente este galimatías jurídico al que evoca la mala praxis normativa estatal pone de relieve la inconveniencia de legislar a salto de mata, porque las consecuencias derivan en el conflicto normativo inevitable en un Estado multinivel ya suficientemente complejo.

\section{Regulación de los consorcios en la LILE}

La regulación del consorcio en la LILE es dispersa; el legislador no lo define, pero en un principio parece inferir su cabida entre los entes locales, y este hecho hace resurgir la vieja polémica sobre su naturaleza jurídica, y por tanto sobre qué régimen jurídico y en qué medida le es éste aplicable.

\section{2.a). Tratamiento del consorcio en La exposición de motivos de LA LILE}

El fundamento jurídico de la LILE viene claramente perfilado en su Exposición de Motivos (EM, en adelante). En este sentido se destacan, en primer término, el respeto al art. 39 de la LRBRL y su importante disposición adicional segunda (acerca del régimen foral vasco), que reguIan notables especialidades del régimen municipal vasco, y que dan cobertura jurídica a la posibilidad, desarrollada en la LILE, de avanzar en la regulación de un modelo municipal propio, en coherencia con lo manifestado por el Tribunal Constitucional en materia de régimen local, especialmente en su Sentencia 214/1989, de 21 de diciembre, referida precisamente a la LRBRL y en particular en su fundamento jurídico 26, pues en ella el tribunal viene a reconocer que las especialidades del régimen local vasco entroncan directamente con el amparo y respeto de los derechos históricos vascos protegidos por la DA $1 .^{a}$ de la Constitución y con su actualización, y llega a decir expresamente que «se comprende,

(38) VELASCO CABALLERO, F., "Los convenios locales en la nueva ley 40/2015,...», op. cit., pág. 2. 
de este modo, que esa garantía constitucional comporte un tratamiento normativo singular propio de ese régimen local, y ello aun frente a los poderes centrales del Estado».

De lo que tratamos es de delimitar hasta dónde llega o puede llegar este tratamiento singular propio del régimen local en lo que a consorcios se refiere, si alcanza a permitir la modulación de la mutación de la naturaleza jurídica de los consorcios denunciada por la doctrina, y en qué medida ello puede derivar en un desplazamiento de la legislación básica estatal.

La EM de la LILE contiene dos previsiones importantes:

La primera es, que partiendo del actual marco básico y de los márgenes de configuración que provee, su pretensión es la de articular un modelo integrado de gobiernos locales que se ensamble correctamente con los diferentes niveles territoriales de gobierno; es decir respeta literalmente el marco normativo institucional vigente.

La segunda, es el alejamiento de la interpretación que la reciente legislación básica estatal realiza del principio de autonomía local. Esta es una clara alusión al contenido de la LRSAL, pues la LRJSP, aunque ya aprobada cuando entró en vigor la LILE no había entrado en vigor todavía y, dadas las inestables circunstancias políticas que se vivían, tampoco se vislumbraba un futuro cierto a su entrada en vigor. Este es el motivo por el que se da la inclusión clara y expresa del consorcio como modo de gestión compartida preferente frente a otras fórmulas de agrupación municipal o gestión integrada, y esto implica que el modelo vasco de autogobierno local se asienta sobre la premisa de la preferencia de las entidades locales de base asociativa (esencialmente mancomunidades) y de los consorcios como medios instrumentales de prestación de servicios locales en aquellos casos en que, por razones de escala o por eficiencia, sea necesario desplazar esa prestación de los municipios a otras instancias (39).

La EM se dicta con vocación de respeto de la legislación básica del Estado, y no determina el carácter de ente local del consorcio, únicamente lo considera como vehículo institucional para el fomento de la prestación compartida de los servicios obligatorios. Pero vemos también que las pretensiones de la LILE, aun siendo legislación de desarrollo de la LRSAL, son distintas a las de ella, y este distanciamiento viene amparado por la legislación vigente dentro del marco constitucional actual.

(39) Expresamente la EM de la LILE, en su apartado $V$ y al describir su noveno objetivo, dispone: "La Ley de Instituciones Locales de Euskadi, respetando las competencias propias de las instituciones forales, se inclina de forma decidida por impulsar las mancomunidades de municipio o, en su caso, los consorcios como vehículos institucionales que fomenten la esa prestación compartida de tales servicios obligatorios". 


\section{2.b). LA REGULACION DEL CONSORCIO EN EL ARTICULADO DE LA LILE}

Podemos decir que la literalidad del articulado de la LILE da cobertura a la regulación de los consorcios en tres ubicaciones diferentes: En el Título I, elTítulo II y el Título VIII.

Dentro delTítulo I; "Objeto y Principios de la Ley», la dicción que el legislador otorga al art. 2 en sus párrafos 1 y 5 de la LILE es confusa en relación a la naturaleza jurídica del consorcio. Este artículo 2 se titula; Entidades locales: potestades y prestación de servicios y literalmente dispone:

"Tendrán la consideración de entidades locales, a efectos de lo previsto en esta ley:

a) El municipio

b) Los concejos y cualesquiera otras entidades locales territoriales de ámbito inferior al municipio, conforme a la normativa foral existente en cada territorio y lo dispuesto en la legislación básica de régimen local.

c) Las mancomunidades de municipio.

d) Las cuadrillas del Territorio Histórico de Álava.

e) Cualesquiera otras entidades que agrupen a varias entidades, bajo la denominación específica que corresponda, conforme a lo dispuesto en esta ley y demás normativa que sea de aplicación.(...)

Estas entidades locales tendrán personalidad jurídica y plena capacidad para el cumplimiento de sus fines».(...)

Lógicamente el art. 2.1e) pudiera suscitar la duda de posibilitar que consorcios y áreas metropolitanas puedan tener la consideración de entes locales a los efectos de la LILE. La filosofía de la Ley se inclina por fórmulas voluntarias y no integradas de asociación, por lo tanto, el foco de atención se pone rápidamente en si los consorcios pudieran considerarse como ente local.

Asimismo el art. 2.5 dispone:

"A las entidades locales previstas en el apartado primero del presente artículo les corresponderán todas las potestades previstas en la legislación básica de régimen local, incluida la declaración de urgente ocupación de bienes y derechos en las expropiaciones por motivos urbanísticos así como la potestad expropiatoria, que ejercerán en su caso, sin perjuicio de lo establecido en las leyes y normas forales que les sean de aplicación.(...)". 
De lo transcrito se deduce que específicamente la literalidad de la LILE evita denominar a los consorcios como entes locales pero los caracteriza como tal, otorgándoles personificación pública y la atribución de potestades públicas. En todo caso, habría que señalar que no pueden ejercer la potestad expropiatoria, puesto que ésta corresponde a la Administración a la que se adscriben o, en su caso, a la Administración territorial competente (40).

Dentro del Título II; «El Municipio y las demás entidades locales vascas", el legislador menciona el consorcio, dentro del Capítulo I dedicado al Municipio. Concretamente en el artículo 10.3, y dispone que la potestad de autoorganización de los municipios se proyecta, asimismo, en el derecho a acordar fórmulas asociativas para la realización de obras o prestación de servicios públicos locales. En especial, la prestación de servicios por mancomunidades y consorcios salvaguarda expresamente, de acuerdo con lo previsto en la Carta Europea de la Autonomía Local, el principio de subsidiariedad y el de proximidad, así como el de autonomía local.

En este caso, el consorcio se vincula intensamente a la prestación de servicios locales como expresión idónea de la potestad de autoorganización del municipio vasco, en consonancia con la Carta Europea de la Autonomía Local.

Si abordamos por último el contenido delTítulo VIII; "Gestión de Servicios públicos locales», en su Capítulo II, titulado "entidades intermedias para la gestión de servicios públicos», vemos que es el lugar en el que la LILE regula más específicamente los consorcios.

Podemos decir que el artículo 101, en su párrafo primero, determina que los municipios podrán crear, modificar o suprimir entidades de base asociativa, al objeto de llevar a cabo una prestación conjunta o compartida de los servicios públicos municipales. Sin embargo, el párrafo tercero del mismo artículo dispone que los órganos forales de los territorios históricos podrán crear, modificar y suprimir dentro de su territorio, entidades de carácter supramunicipal que agrupen a varios municipios, de acuerdo con la legislación básica de régimen local o la normativa foral correspondiente, o en su caso, según lo previsto en la presente ley, haciendo alusión a comarcas, aunque no se mencionen expresamente.

El art. 102 de la LILE intitulado; "entidades locales de base asociativa» dispone, en su apartado primero, literalmente:

(40) ENÉRIZ OLAECHEA, F. J., "La tipología de las entidades locales y las fórmulas institucionales de intermunicipalidad", en Revista Vasca de Administración Pública, núm. 107-II, enero-abril 2017, pág. 204. 
"1.-Las mancomunidades de municipios y otras fórmulas asociativas de entidades locales podrán constituirse como fórmula adecuada para la gestión compartida de realización de obras y prestación de los servicios públicos derivados de los ámbitos materiales previstos en el art. 17 de la presente ley, y de los servicios que en todo caso deban prestar los municipios, así como cuando respecto de estos últimos sea necesario ofrecer por parte del municipio afectado una solución institucional que represente una mejora en los costos efectivos o en los estándares de calidad del servicio, de acuerdo con lo establecido en la presente ley y en lo que se determine en la normativa foral correspondiente».

Este precepto podría suscitar de nuevo la duda de si con estas "otras entidades locales de base asociativa" la LILE se refiere a los consorcios. La ley no lo concreta. Son los artículos 104 a 106 los que dedica expresa y específicamente a la regulación de los consorcios, y lo hace configurándolos expresamente como instrumentos de cooperación económica, técnica y administrativa para la prestación de servicios públicos locales. Asimismo hace posible su integración con otras Administraciones Públicas y entidades privadas sin ánimo de lucro que persiguen fines de interés público concurrentes con los de las administraciones públicas que constituyan esas entidades. Por lo tanto la LILE en ocasiones parece advertir la diferenciación entre entidades locales y consorcios, aunque tampoco lo hace de forma clara.

Además de lo anterior, la LILE delimita los consorcios como fórmulas preferentes para la gestión compartida de los servicios mínimos obligatorios municipales en aquellos casos en que sea necesario ofrecer por parte del municipio afectado una solución institucional que represente una mejora en los costes efectivos o en los estándares de calidad del servicio, es decir, cuando la Diputación Foral haya de actuar en ejercicio de sus facultades de coordinación.

La cuestión sobre la naturaleza jurídica del consorcio regulado en la LILE fue debatida en el seno de un grupo de trabajo constituido por EUDEL que contribuyó a la elaboración del documento denominado "Consideraciones Urgentes sobre algunos aspectos de la Ley de Instituciones Locales de Euskadi». En dicho documento se analizan, entre otras cuestiones, las dificultades que entraña la literalidad de estos preceptos para la determinación del régimen jurídico aplicable a los consorcios locales vascos(41).

(41) El documento, en cuya reflexión y elaboración tuve oportunidad de participar, puede encontrarse en EUDEL. Web: http://www.eudel.eus/es/documentos/otros_documentos_0 (Última consulta 12/12/1016). 
Por un lado, resulta obvio que la legislación básica del Estado, más aun a partir de la LRJSP, dota a los consorcios de un carácter de instrumental obvio al incluirlos expresamente en el sector público institucional, cerrando definitivamente la tendencia ya marcada por la LRSAL y la interpretación que de la misma realiza elTC.

En algunos casos la LILE es muy clara, previendo que los servicios públicos que no se puedan prestar directamente por el municipio lo sean por otras entidades locales de base asociativa (artículos 2.2, 2.3, 19, 93.3, etc.), pero en otros preceptos se admite explícitamente que sean asimismo consorcios los que puedan prestar tales servicios (artículos 10.3 y 104). La fórmula consorcial según la LILE es, por tanto, una modalidad organizativa idónea para prestar servicios públicos municipales en clara contravención a la literalidad de la LRSAL.

Como se concluyó en el grupo de trabajo de EUDEL, bajo esos presupuestos, cabría afirmar la existencia de dos interpretaciones:

La primera supondría que, tras ese marco normativo básico expuesto con detalle, los consorcios tienen efectivamente carácter instrumental y no son propiamente hablando entidades locales, con las consecuencias que ello conlleva desde algunos puntos de vista (adscripción a una administración local o foral matriz, no dispondrían de puestos reservados para funcionarios con habilitación de carácter nacional, no se inscribirían en el Registro de entidades locales, etc.). Esta tesis parece la más aceptable dentro del marco normativo citado, y ello implicaría que las previsiones recogidas en normativa foral que predicaran el carácter de entidad local de los consorcios se verían desplazadas por la normativa básica citada. En cualquier caso, ello no impediría que los consorcios siguieran siendo una forma de gestión de servicios públicos municipales $y$, además, según prevé la propia LILE, de carácter preferente.

La segunda lectura es que, con base en ese apartado e) del artículo 2.1 de la LILE, podría caracterizarse a los consorcios, cuando la normativa foral así lo previera, como entidades locales que tendrían esa finalidad de "agrupación pública» con el objeto de prestar servicios públicos. La normativa foral jugaría en este caso como una suerte de excepción a la normativa básica. Pero esta interpretación choca con el último inciso del enunciado que expresamente acota esa caracterización "a lo dispuesto en esta ley y demás normativa que sea de aplicación»; inciso final en el que cabe incluir a la legislación básica y también con la propia EM de la LILE que respeta la legislación básica estatal.

Además esta segunda interpretación es, a día de hoy, poco garantista, porque la consideración del consorcio como ente local en la Ley Foral 23/2014, de 2 de diciembre, del Parlamento de Navarra fue objeto de recurso de inconstitucionalidad por el Estado, que determinaba que el consorcio debía de estar adscrito, en todo caso, a una Administración Pública 
y por lo tanto ello era incompatible con su consideración de ente local. Finalmente, el Estado y la Comunidad Foral de Navarra Ilegaron a un acuerdo en la Junta de Cooperación, en virtud del cual Navarra se ha comprometido a modificar su legislación y adecuarla a la básica estatal. Y lo cierto es que, aunque el acuerdo sólo vincula a las partes, la interpretación del Estado no deja fisuras y es excluyente de la consideración del consorcio como ente local.

Siguiendo el discurso de MARTÍN MATEO podría plantearse la caracterización de ente local de aquellos consorcios locales que prestan servicios públicos locales y están integrados exclusivamente por Administraciones Públicas, así como la aplicación a ellos de una legislación especial, como es la local, y por lo tanto la emanada de los órganos forales en cumplimiento del marco normativo existente en la CAPV. No obstante esta interpretación es también forzada, pues ello dependería, en primer término, de la Administración a la que deba adscribirse el consorcio, y si en su caso resultase ser la local, en segundo término, dependería de la dimensión que pudiera otorgarse al régimen de adscripción.

\section{Conclusiones}

PRIMERA: La evolución de la legislación básica estatal sobre el régimen jurídico del consorcio ha pasado de la desregulación total en el ámbito estatal al exceso de regulación con carácter básico, lo cual ha restringido tanto la capacidad de autorregulación de los propios consorcios a través de sus estatutos, como la capacidad normativa de los Comunidades Autónomas con competencias en la materia. Esta disminución de la capacidad normativa es especialmente singular en la Comunidad Autónoma del País Vasco porque, desde el momento en que difícilmente puede extraerse la naturaleza de ente local del consorcio, también los TTHH ceden su competencia a la vis expansiva de la legislación básica estatal y dejan de tener competencia exclusiva en la materia cuando el consorcio estuviera constituido por entidades pertenecientes a suTerritorio Histórico.

SEGUNDA: A pesar de que la legislación básica estatal ha sido dictada al albur de la consecución de un régimen jurídico general aplicable a todos los consorcios, aun buscando la uniformidad, se sigue manteniendo una dualidad de regímenes sobre el consorcio; por un lado, el aplicable a los consorcios locales y por otro lado, el aplicable al resto de consorcios. Se evidencia una especial preocupación del legislador por diferenciar el consorcio local, negar su naturaleza de ente local y extraerla de la «materia» régimen local. Probablemente sea éste el motivo por el que no se 
consigue toda la uniformidad pretendida, pero sí la centralización competencial en manos del Estado para su regulación.

TERCERA: La regulación de la LILE se ve afectada por la legislación básica estatal que ha entrado posteriormente en vigor, esto es la LRJSP. Es evidente que el legislador básico prima más el carácter instrumental del consorcio que su condición de instrumento de cooperación subsidiario, pero en el ámbito local, gracias a la pervivencia de la LRSAL, el consorcio se convierte en un instrumento idóneo para la coordinación de servicios municipales en municipios de menos de 20.000 habitantes, y por lo tanto se desnaturaliza porque pierde su componente de voluntariedad.

CUARTA: La LILE se resiste a la LRSAL, y configura un régimen de prestación de servicios públicos obligatorios singular para las entidades locales vascas de menos de 20.000 habitantes, en contraposición a la regulación aportada por la LRSAL. Este régimen especial potencia la figura del consorcio como fórmula preferente de prestación en los casos en que la Diputación Foral necesitara utilizar fórmulas de coordinación, de manera que la mutación de la naturaleza jurídica del consorcio en el ámbito local se modula en la CAPV, en la que la nota de asociacionismo voluntario de los municipios vascos es clave también para la prestación de servicios en los supuestos de prestación integrada de los mismos. Asociacionismo y voluntariedad; la libre decisión del Municipio sobre la manera de gestionar los servicios públicos locales está en el núcleo de la autonomía local configurada por el legislador vasco.

\section{Bibliografía}

APARISI APARISI, M. ${ }^{\text {a }}$ Carmen, "Los consorcios locales tras la LRSAL y la determinación de sus regímenes financiero y contable», en El derecho. Web: http://www.elderecho.com/tribuna/administrativo/Consorcios-locales-regulacion-regimenes-financiero-LRSAL_11_1026430001.html (Última consulta 25/09/2017).

CASTILLO BLANCO, Federico A., "Los consorcios de entidades locales: análisis y valoración de la nueva legislación de régimen local», en $R e$ vista de Administración Pública, núm. 124, 1991, págs. 397-416.

CASTILLO BLANCO, Federico A. "Los consorcios administrativos: especial referencia a los consorcios de entidades locales en la legislación andaluza», Revista Andaluza de Administración Pública, núm. 42, 2001, págs. 95-144.

CASTILLO BLANCO, Federico A. "La nueva regulación de los consorcios públicos: interrogantes y respuestas sobre su régimen jurídico de su 
personal (1)». Revista Vasca de Administración Pública, núm. especial 99-100, mayo-diciembre 2014, págs. 887-920.

CASTILLO BLANCO, Federico A. "La disolución y liquidación de los consorcios administrativos". REALA, Nueva Época. Revista de Estudios de la Administración local y Autonómica, núm. 7, mayo 2017, págs. 19-44.

CASTILLO BLANCO, Federico A. "La incidencia de la nueva Ley de Régimen Jurídico del Sector Público en los instrumentos de cooperación del Estado Autonómico: especial referencia a los consorcios públicos». Web: http://laadministracionaldia.inap.es/noticia.asp?id=1507211 (Última consulta 20/09/2017).

DEL GUAYO CASTIELLA, Iñigo, "Formas de gestión de los servicios públicos locales en la Ley núm. 2/2016, de Instituciones Locales de Euskadi», en Revista Vasca de Administración Pública, núm. 107-II, enero-abril 2017, págs. 301-347.

ENÉRIZ OLAECHEA, Francisco Javier, "La tipología de las entidades locales y las fórmulas institucionales de intermunicipalidad". $R e-$ vista Vasca de Administración Pública, núm. 107-II, enero-abril 2017, págs. 173-212.

FERREIRA FERNÁNDEZ, A. Javier. "Los consorcios del sector público autonómico. Un instrumento para la gestión conjunta de servicios públicos». Dereito Monográfico: Estudios sobre la modernización administrativa, 2001, págs. 95-143.

FERREIRA FERNÁNDEZ, A. Javier. «El desarrollo de la fórmula consorcial en el ámbito autonómico: de los consorcio locales a los consorcios autonómicos». Dereito Vol. 18, núm.1, 2009, págs. 5-32.

FERREIRA FERNÁNDEZ, A. Javier. "Los consorcios del sector público autonómico: naturaleza y características». Revista de Estudios de la Administración Local y autonómica, núm. 310, 2009, págs. 169-203. Web: http:// revistasonline.inap.es/index.php?journal=REALA\&page=issue\&op=vie w\&path\%5B\%5D=633 (Última consulta 07/10/2017).

GALLARDO ROMERA, Elvira. "La nueva administración institucional en la ley 40/2015, de 1 de octubre, de régimen jurídico del sector público». Actualidad Administrativa, núm. 10, Sección Actividad económica de la Administración. Ed. La ley, octubre 2016, pág. 10.

GARCÍA RUBIO, Fernando, "Los consorcios locales en el proyecto de ley de Régimen Jurídico del Sector Público. Reflexiones necesarias», en Documentación Administrativa. Nueva época, núm. 2, enero-diciembre, 2015. Web: https://dialnet.unirioja.es/servlet/autor?codigo=193103 (Última visita 23/10/2017).

JIMÉNEZ ASENSIO, Rafael, “¿Réquiem por los consorcios? Notas sobre el nuevo régimen jurídico de los consorcios tras la $L R S A L$, en blog de 7 de junio de 2014, Web: www.estudiconsultoria.com (Última consulta 10/7/2014). 
JIMÉNEZ ASENSIO, Rafael, «El sector Público Local tras la Ley 40/2015: retos inmediatos y cuestiones abiertas (1)", en blog de 22 de septiembre de 2016. Web: https://rafaeljimenezasensio.com/2016/09/ (Última consulta $28 / 12 / 2016)$.

LARRAZABAL BASAÑEZ, Santiago. «Zume hauekin...ekin lanari. Reflexiones sobre la génesis, naturaleza e inserción de la Ley de Instituciones Locales de Euskadi en el peculiar sistema de fuentes del derecho Vasco", en Revista Vasca de Administración Pública, núm. 107-II, enero-abril 2017, págs. 21-55.

MARTÍN MATEO, Ramón. "Los consorcios locales. Una institución en auge», en Revista de Administración Pública, núm. 129. Septiembrediciembre 1992, págs. 7-18.

MARTÍN MATEO, Ramón. "El consorcio como institución jurídica», en Revista de Administración Pública, núm. 61, 1970, págs. 9-42.

MARTÍNEZ FERNÁNDEZ, Faustino, "Mancomunidades e Consorcios", en Revista Gallega de Administración Pública, núm. 34, enero-abril de 2005, págs. 183-210.

NIETO GARRIDO, Eva. "El consorcio como instrumento de cooperación administrativa", en REALA, Revista de Estudios de la Administración local y Autonómica, núm. 270, 1996, págs. 327-361. Web: https://revistasonline.inap.es/index.php?journal=REALA\&page=article\&op=view\&path\%5 B\%5D=8916\&path\%5B\%5D=8965 (Última consulta 07/10/2017).

NIETO GARRIDO, Eva. El consorcio administrativo, Cedecs, Barcelona, 1997. NIETO GARRIDO, Eva, "La naturaleza jurídica del consorcio administrativo a propósito de la sentencia delTribunal Supremo de 30 de abril de 1999", en $R E A L$, Revista de Estudios de la Administración Local, núm. 285, enero-abril de 2001, págs. 249-254.

PARRA MUÑOZ, Juan Francisco, "A vueltas con la naturaleza jurídica del Consorcio", en Actualidad Administrativa, Sección Doctrina, Tomo 2. Ed: La Ley, 2001, págs. 799-826.

PÉREZTORRENTE, José Antonio, "Los Consorcios", en Revista catalana de dret Públic, núm. 96, diciembre 1996, págs. 51-66.

SANTAMARÍA PASTOR, Juan Alfonso. Principios del Derecho Administrativo General. Tomo I, 2. ${ }^{a}$ Ed., lustel, Madrid 2009, págs. 527-528.

STS 2955/1999, de 30 de abril. Web: http://www.poderjudicial.es/search/ contenidos.action?action=contentpdf\&databasematch=TS\&reference $=3$ 167380\&links=\%22MANUEL\%20GODED\%20MIRANDA\%22\&optimize=2 0030906\&publicinterface=true (Última consulta 23/10/2017).

STC 41/2016, de 3 de marzo. BOE, núm. 85, de 8 de abril, págs. 25009-25010 y 25020. Web: https://www.boe.es/boe/dias/2016/04/08/pdfs/BOE-A-20163407.pdf (Última consulta 02/03/2018).

STC 93/2017, de 6 de julio. BOE, núm. 191, de 11 de agosto. Web: https:// www.boe.es/boe/dias/2017/08/11/pdfs/BOE-A-2017-9652.pdf (Última consulta 02/03/2018). 
SOSA WAGNER, Francisco. "A vueltas con los consorcios", Web: http:// www.administracionpublica.com/a-vueltas-con-los-consorcios/ (última consulta 07/10/2017).

TOSCANO GIL, Francisco, "La nueva regulación del consorcio local en la ley de Autonomía Local de Andalucía», en REALA, Revista de Estudios de la Administración local y Autonómica, núm. 313-314, mayo-diciembre 2010, págs. 105-123.

TOSCANO GIL, Francisco, "La definición del consorcio local como entidad local en la legislación autonómica», en Cuadernos de Derecho Local $(Q D L)$, núm. 27, Fundación Democracia y Gobierno Local, octubre de 2011, págs. 36-47.

TOSCANO GIL, Francisco, "La reforma del régimen legal de los consorcios administrativos: ¿modificación de sus notas características o mutación de su naturaleza jurídica?, en Anuario de Gobierno Local, núm. 1, 2014, págs. 75-103.

TOSCANO GIL, Francisco, "El consorcio administrativo en la encrucijada», en REALA, Revista de Estudios de la Administración local y Autonómica, núm. 3, 2015. Web: https://revistasonline.inap.es/index.php?journal=REALA\&page=article\&op=view\&path \%5B\%5D=10239\&path\%5B\%5D=107 28 (Última consulta 07/10/2017).

TOSCANO GIL, Francisco, "Otra vez los consorcios administrativos: novedades introducidas por la Ley 40/2015 de régimen jurídico del sector público", en Revista Vasca de Administración Pública, núm. 105, MayoAgosto 2016, págs. 473-513.

VELASCO CABALLERO, Francisco. "Los convenios locales en la nueva ley 40/2015, de Régimen Jurídico del Sector Público». Instituto de derecho Local. UAM blog. 13 de noviembre de 2015. Web: http://www.idluam. org/blog/?p=363 (Última consulta 07/10/2017).

Trabajo recibido el 9 de enero de 2018

Aceptado por el Consejo de Redacción el 16 de febrero de 2018 
LABURPENA: Euskadiko Toki Erakundeei buruzko apirilaren 7ko 2/2016 Legeak ez du zehaztasunez erregulatzen partzuergoen irudiaren izaera juridikoa, eta, bestetik, lege hori indarrean jartzeak baliogabetu egin du oinarrizko legegileak Sektore Publikoaren Araubide Juridikoari buruzko urriaren 1eko 40/2015 Legeari eman zion vacatio legis-a. Bada, bi egitate horiek ziurgabetasuna eragin dute azken lege horrek Euskal Autonomia Erkidegoko legearen gainean dituen ondorioen inguruan. Euskadiko tokiko partzuergoen gaur egungo izaera juridikoari hurbilpena egin nahi dio ikerketa honek, Estatuko oinarrizko araudiaren bilakaeraren ikuspegitik, eta partzuergoen eraketak dituen berezitasunak mugatzen lagundu nahi du.

GAKO HITZAK: Tokiko partzuergoak. Erakundeen sektore publikoa. Euskadiko Toki Erakundeei buruzko Legea.

RESUMEN: La indefinición con la que la Ley 2/2016, de 7 de abril, de Instituciones Locales de Euskadi, regula la naturaleza jurídica de la figura de los consorcios, unido al hecho de que tras su entrada en vigor concluyera la vacatio legis que el legislador básico otorgó a la Ley 40/2015, de 1 de octubre, de Régimen Jurídico del Sector Público, ha propiciado incertidumbre sobre los efectos de esta ley sobre la vasca. Este estudio tiene la pretensión de acercarse a la naturaleza jurídica actual de los consorcios locales vascos desde la perspectiva de la evolución normativa básica estatal y contribuir a delimitar las particularidades de su configuración.

PALABRAS CLAVE: Consorcio local. Sector público institucional. Ley de Instituciones Locales de Euskadi.

ABSTRACT: The lack of definition that Act 2/2016 of April $7^{\text {th }}$, of Local Entities of Euskadi uses to regulate the legal nature of the institution of consortiums, together with the fact that its entry into force exhausted the vacatio legis granted by the basic legislator to Act 40/2015 of October $1^{\text {st }}$ of the Legal Regime of the Public Service has resulted in uncertainty about the effects of that Act upon the Basque one. This study attempts to approach to the current legal nature of Basque local consortiums from the perspective of the State basic normative evolution and to contribute to pinpoint the particularities of their set up.

KEYWORDS: Local consortium. Institutional Public Sector. Act of Local Entities of Euskadi. 